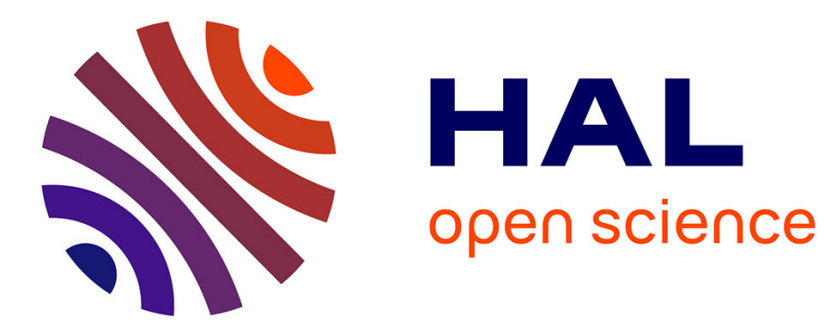

\title{
The Heidelberg polarized alkali source
}

E. Steffens, W. Dreves, P. Egelhof, D. Kassen, W. Weiss, P. Zupranski, D. Fick

\section{To cite this version:}

E. Steffens, W. Dreves, P. Egelhof, D. Kassen, W. Weiss, et al.. The Heidelberg polarized alkali source. Revue de Physique Appliquée, 1977, 12 (10), pp.1567-1570. 10.1051/rphysap:0197700120100156700 . jpa-00244368

\section{HAL Id: jpa-00244368 https://hal.science/jpa-00244368}

Submitted on 1 Jan 1977

HAL is a multi-disciplinary open access archive for the deposit and dissemination of scientific research documents, whether they are published or not. The documents may come from teaching and research institutions in France or abroad, or from public or private research centers.
L'archive ouverte pluridisciplinaire HAL, est destinée au dépôt et à la diffusion de documents scientifiques de niveau recherche, publiés ou non, émanant des établissements d'enseignement et de recherche français ou étrangers, des laboratoires publics ou privés. 


\title{
THE HEIDELBERG POLARIZED ALKALI SOURCE
}

\author{
E. STEFFENS, W. DREVES, P. EGELHOF, D. KASSEN, W. WEISS, P. ZUPRANSKI (*) and D. FICK
}

Max-Planck-Institut für Kernphysik, Heidelberg, R.F.A.

and I. Inst. für Exp. Physik, University of Hamburg, R.F.A.

\begin{abstract}
Résumé. - Une source à faisceau atomique pour des ions de lithium négatifs polarisés est en service à l'accélérateur Tandem EN de Heidelberg depuis 1974. Un ionisateur de surface très efficace est employé. Des faisceaux polarisés vectoriel et tensoriel de ${ }^{6} \mathrm{Li}(I=1)$ et ${ }^{7} \mathrm{Li}(I=3 / 2)$ on été produits avec un courant à la cible allant jusqu'à $150 \mathrm{nA}$ de $\mathrm{Li}^{3+}$. La polarisation tensorielle de rang 2 des deux faisceaux a été étalonnée sur une échelle absolue. Des résultats préliminaires de production d'un faisceau de ${ }^{23} \mathrm{Na}$ polarisé sont donnés.
\end{abstract}

Abstract. - An atomic beam source for negative polarized lithium ions is operated at the Heidelberg EN-Tandem since 1974. A highly efficient surface ionizer is used. Vector and tensor polarized beams of ${ }^{6} \mathrm{Li}(I=1)$ and ${ }^{7} \mathrm{Li}(I=3 / 2)$ have been produced with currents up to $150 \mathrm{nA}$ of $\mathrm{Li}^{3+}$ at the target. The second rank tensor polarization of both beams is calibrated absolutely. Preliminary results of producing a polarized ${ }^{23} \mathrm{Na}$ beam are reported.

Sources for negative polarized light ions ( $p$ and $d$ ) are frequently used at Tandem accelerators as a tool in nuclear physics $[1,2]$. Attempts to produce negative polarized beams of heavier particles have resulted in the Los Alamos source for tritium ions [3] and the Heidelberg source for alkali ions $[4,5]$ which

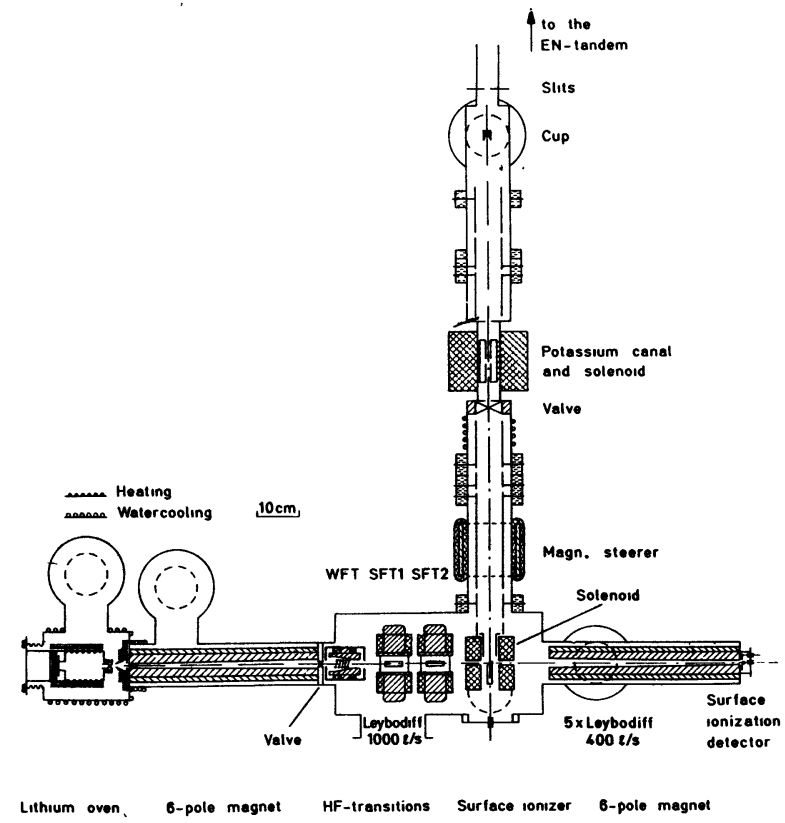

FIG. 1. - Source for negative polarized alkali ions.

$\left(^{*}\right)$ On leave from the Instytut Badán Jadrowych, Warsaw. is subject of the present paper. An interesting aspect of polarized alkali beams is the large nuclear deformation of ${ }^{7} \mathrm{Li}$ and ${ }^{23} \mathrm{Na}$ which seems to be of great interest in heavy ion physics [6].

1. Polarized atomic beam. - The ion source shown in figure 1 makes use of the atomic beam

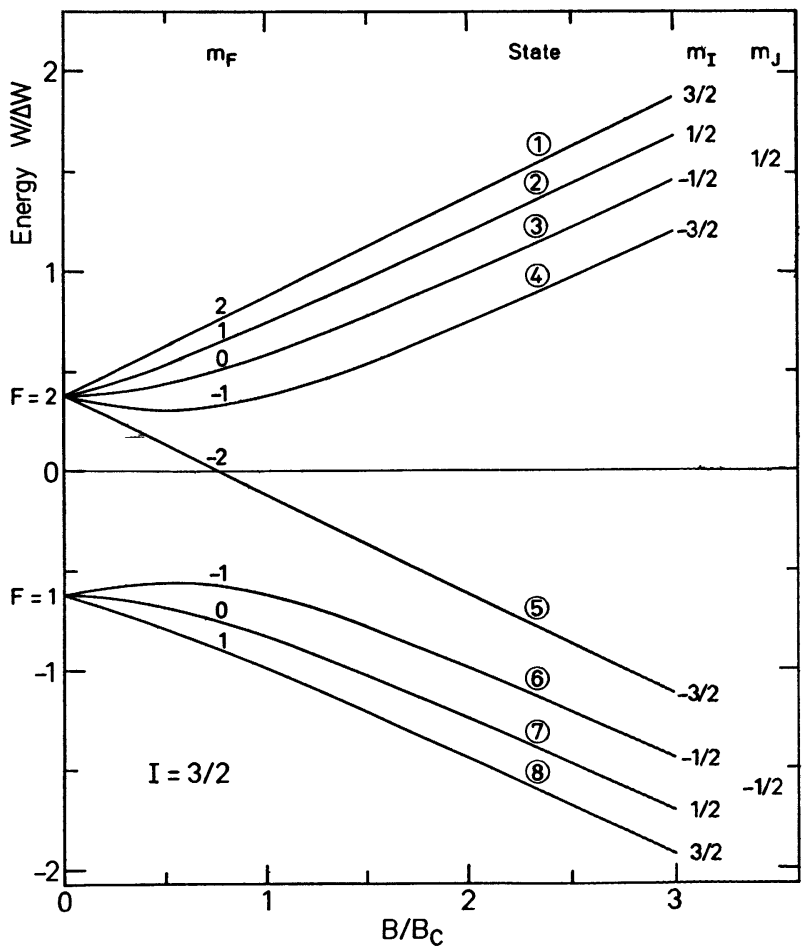

FIG. 2. - Hfs splitting in an external magnetic field for $J=1 / 2$, $I=3 / 2\left({ }^{7} \mathrm{Li},{ }^{23} \mathrm{Na}\right)$. The critical fields $B_{\mathrm{c}}$ are given in table $\mathrm{I}$. 
method [7]. It is based on the hyperfine splitting of the alkali atom with $J=1 / 2$ and nuclear spin $I=1$ for ${ }^{6} \mathrm{Li}$ and $I=3 / 2$ for ${ }^{7} \mathrm{Li}$ and ${ }^{23} \mathrm{Na}$ (see Fig. 2).

Alkali metal vapour leaves a heated oven through a Laval nozzle and the atomic beam is formed by a system of hot and cold collimators and separated in the Stern-Gerlach field of a permanent 6-pole magnet. Atoms with $m_{J}=+1 / 2$ only pass the magnet. In the case of a $7 \mathrm{Li}$ beam the upper four states 1, 2, 3 and 4 are occupied behind the magnet (Fig. 2).

Nuclear polarization is achieved by a system of high frequency transitions [7, 8]. It consists of a weak field transition (WFT) and two strong field or 2-level transitions (SFT 1 and 2) following the adiabatic passage method [7].

The SFTs are induced by electromagnetic radiation with frequency of the order $\Delta W / h(\Delta W=$ zero field hyperfine splitting, see table I) in a static magnetic field. On technical reasons the hf and static fields are oriented parallel which allows for the induction of $\sigma$-transitions only $\left(\Delta F=1, \Delta m_{F}=0\right)$. The static fields are produced by magnets with parallel pole tips and additional gradient coils.

\section{TABLE I}

Relevant figures for the stable lithium and sodium isotopes

\begin{tabular}{lrrc} 
& \multicolumn{1}{c}{$6 \mathrm{Li}$} & \multicolumn{1}{c}{${ }^{\mathrm{Li}}$} & \multicolumn{1}{c}{$23 \mathrm{Na}$} \\
\cline { 2 - 4 } & \multicolumn{1}{c}{1} & \multicolumn{1}{c}{$3 / 2$} & \multicolumn{1}{c}{$3 / 2$} \\
$\Delta W / h(\mathrm{MHz})$ & 228.2 & 803.5 & 1771.6 \\
$B_{\text {crit }}(\mathrm{mT})$ & 8.2 & 28.8 & 63.3 \\
$Q_{\mathrm{s}}(\mathrm{mb})$ & -0.8 & -40 & 140
\end{tabular}

For the dynamic field two coupled $\lambda / 2$ strip lines are used in a box with silver plated inner walls forming a resonator of high $Q$ [8] (1). The resonance lenght (e.g. $\lambda / 2=0.5 \mathrm{~m}$ for $300 \mathrm{MHz}$ ) is reduced to manageable dimensions by connecting the ends of the strip lines to ground by capacitors as shown in figure 3. Hf power of a few watts is fed in from a power signal source [9] tunable in the range 0.2 to 3.0 GHz. The frequency is set to maximum output of the monitor loop (Fig. 3), i.e. maximum strength of the hf field. The transition is then adjusted by tuning the static field.

The function of the hf transitions is controlled by a second 6-pole magnet behind the ionizer (see Fig. 1). Only atoms whose $m_{J}$ has not been changed by the transitions, reach the atomic beam detector behind this magnet, e.g. for ${ }^{7} \mathrm{Li}$ the detector current should drop to $3 / 4$ if one of the four upper hfs states is converted into one of the lower states.

(1) G. Heidenreich, University of Basel, priv. communication.

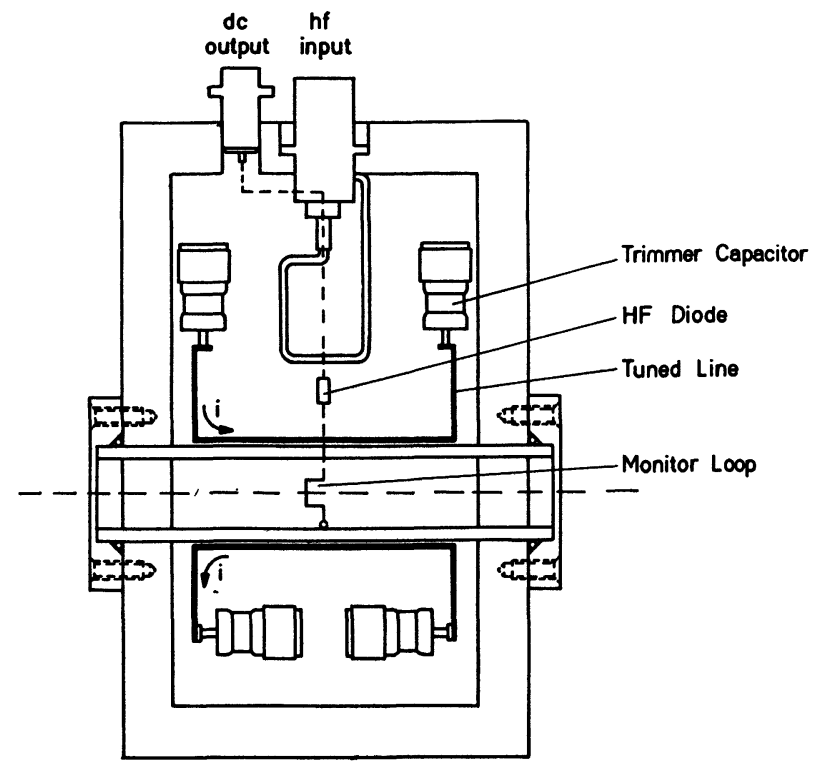

FIG. 3. $-300 \mathrm{MHz}-$ resonator for the production of the dynamic field. The length of the tuned line is $4 \mathrm{~cm}$.

In figure 4 the detector current is shown as function of the static magnetic field in the strong field transition. The frequency was $1010 \mathrm{MHz}$ and the three curves were recorded at different values of the current in the gradient coil. The pronounced dips are associated with the three possible ${ }^{7} \mathrm{Li} \sigma$-transitions, which become broader with increasing gradient. The fall-off does not reach entirely the ideal value $3 / 4$ which indicates slightly incomplete transitions.

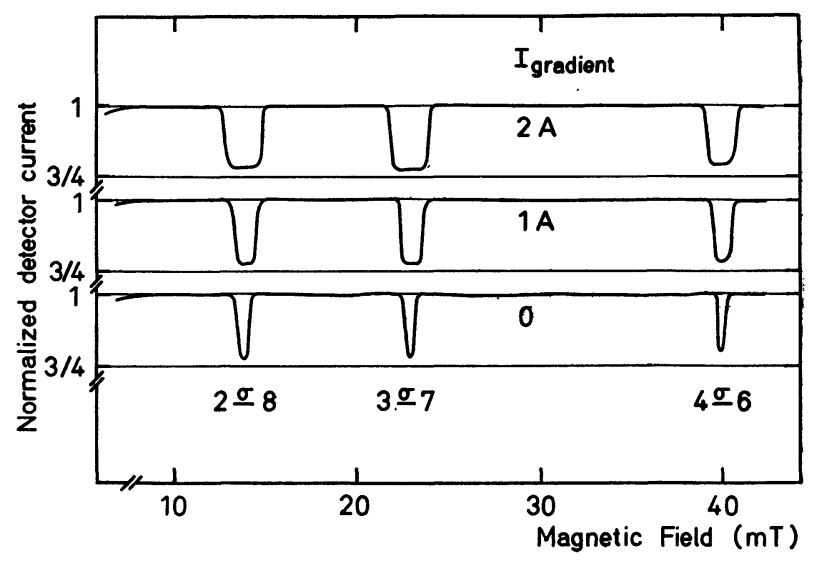

FIG. 4. $-{ }^{7} \mathrm{Li} \sigma$-transitions as function of the static field, detected by the 2nd 6-pole magnet, for different currents in the gradient coil. The frequency was $1010 \mathrm{MHz}$. The numbering of states refers to figure 2.

Some of the possible combinations of polarization components are given in table II. The $t_{k \mathrm{o}}$ denote the spherical tensor components $[10,11]$ where rank $k$ is limited by $k \leqslant 2 I\left(k=1,2\right.$ for ${ }^{6} \mathrm{Li}$ and $1,2,3$ for ${ }^{7} \mathrm{Li},{ }^{23 \mathrm{Na}}$ ). Combinations $\mathrm{a}$ and $\mathrm{b}$ are suitable for measuring effects of the first rank or vector component, $\mathrm{c}$ and $\mathrm{d}$ for effects of the second rank polarization or 


\section{TABLE II}

Possible combinations of polarization components (full efficiency of the hf transitions assumed)

$$
\begin{aligned}
& I=1\left({ }^{6} \mathrm{Li}\right)
\end{aligned}
$$

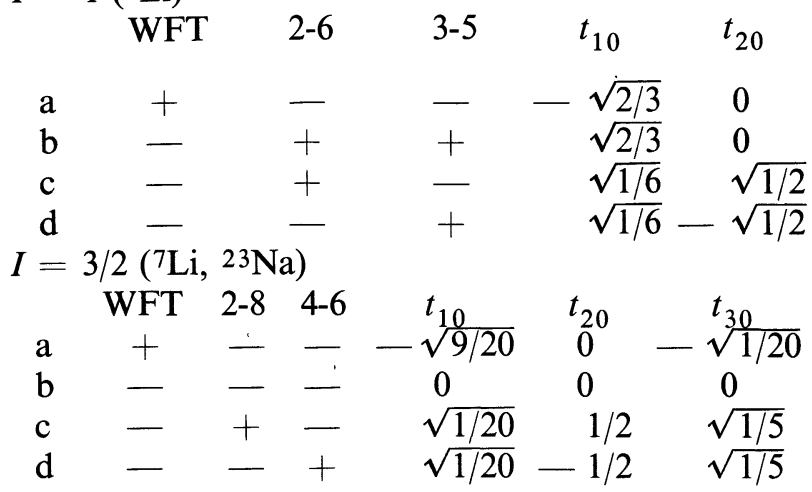

alignment. For ${ }^{6} \mathrm{Li}$ maximum alignment $t_{20}$ can be obtained whereas for ${ }^{7} \mathrm{Li}$ the ideal value of the alignment $t_{20}$ obtainable by the transitions is limited to $50 \%$ of the maximum value.

The polarization can be changed between different combinations without any steering effects by switching the hf. During the experiments the transitions are switched automatically in time intervals of a few seconds, coupled by a routing system to the data acquisition.

2. Surface ionizer. - The atomic beam is ionized to positive ions on the oxidized surface of a hot tungsten strip. Due to the high work function of the W-O surface of more than $6 \mathrm{eV}$, lithium atoms

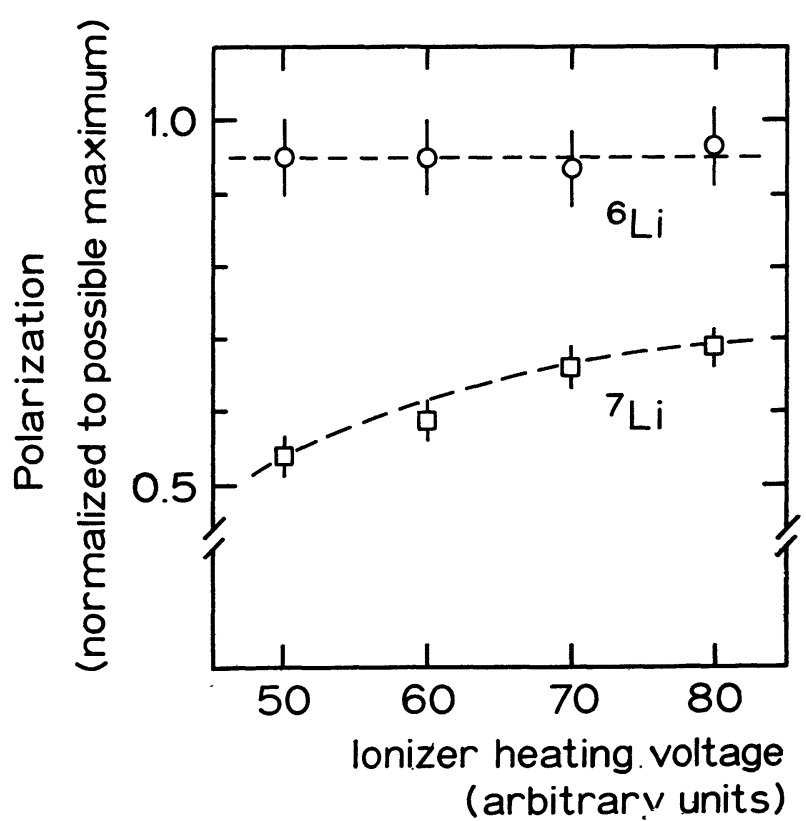

FIG. 5. - Polarization of the accelerated beam as function of the ionizer heating voltage. The polarization is normalized to the maximum value obtainable by the hf transitions (see table II). A voltage of 60 units corresponds to $1000^{\circ} \mathrm{C}$. whose ionization energy is $5.4 \mathrm{eV}$, are ionized nearly $100 \%$ efficient [12].

In figure 5 the polarization of the accelerated beam is shown as function of the ionizer heating voltage. Although the ions stick to the surface for times of the order 1 to $100 \mathrm{~ms}$ [13], no serious depolarization takes place. The adsorption times decrease with increasing temperature, i.e. heating voltage, by two orders of magnitude from the lowest to the highest value investigated.

The ${ }^{6} \mathrm{Li}$ polarization was found to be $95 \%$ of the maximum value independent of temperature. On the other hand ${ }^{7} \mathrm{Li}$ showed a pronounced rise for higher temperatures up to about $70 \%$ of the maximum value. Recent measurements indicate that above $1300{ }^{\circ} \mathrm{C}$ the polarization reaches a saturation value and that the discrepancy to the ideal value is partly due to incomplete $\mathrm{hf}$ transitions.

The different behaviour of the two beams can probably be understood qualitively by the interaction of the large quadrupole moment of $7 \mathrm{Li}$ (Table I) with fluctuating electric field gradients of the surface [14].

\section{Lithium currents and preliminary ${ }^{23} \mathrm{Na}$ results.} - Currents of 20 to $30 \mu \mathrm{A}$ positive polarized lithium ions are extracted from the ionizer surface and converted to negative ions in potassium vapour at $10 \mathrm{keV}$ energy. The total efficiency is about $1 \%$. Currents of $24 \mathrm{keV}$ negative ions of typically 150 and up to $260 \mathrm{nA}$ are obtained behind the Wien filter [7] which serves as spin precessor. $\mathrm{Li}^{3+}$ target currents are typically 50 to 100 and up to $150 \mathrm{nA}$.

First attempts to produce a polarized beam of ${ }^{23} \mathrm{Na}$ ions have resulted in $100 \mathrm{nA}$ negative ions of $46 \mathrm{keV}$ and an accelerated beam of $70 \mathrm{nA}{ }^{23 \mathrm{Na}^{7+}}$ and $48 \mathrm{MeV}$ energy. The $(7+)$-state was chosen because this one is expected to have the weakest hyperfine interaction among the charge states available at an EN-tandem.

The polarization measurements will be done similar to the ${ }^{7} \mathrm{Li}$ calibration (see below). The $2 \mathrm{GHz}$ resonators necessary for producing an aligned ${ }^{23} \mathrm{Na}$ beam are presently under construction.

4. $6 \mathrm{Li}$ polarization. - The alignment of the $6 \mathrm{Li}$ beam was calibrated in the ${ }^{2} \mathrm{H}\left({ }^{6} \overrightarrow{\mathrm{Li}}, \alpha\right){ }^{4} \mathrm{He}$ reaction using the known deuteron analyzing powers for the same reaction ([15], and Ref. therein). It can be shown that for $\theta_{\mathrm{cm}}=90^{\circ}$ deuteron and ${ }^{6} \mathrm{Li}$ analyzing powers are equal.

In figure 6 the spin-dependent part-of the cross section for $\theta_{\mathrm{cm}}=90^{\circ}$ is shown (black dots) as function of the magnetic field in the Wien filter which is proportional to the precession angle. The data points are well reproduced by the hatched error band containing the beam alignment $t_{20}$ as the only free parameter. The result of the fit is:

$$
t_{20} / t_{20}(\max )=0.95 \pm 0.03
$$




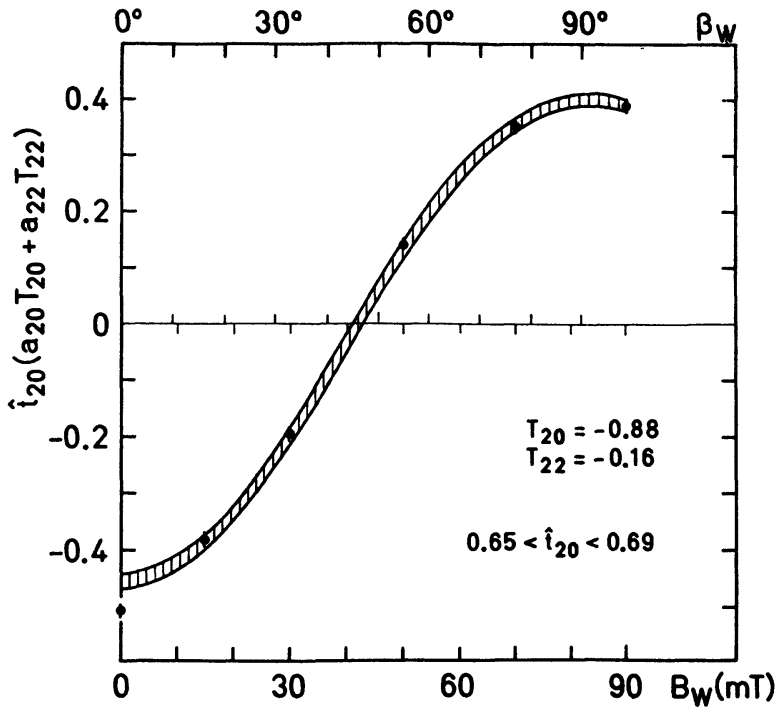

Fig. 6. - Calibration of the ${ }^{6} \mathrm{Li}$ polarization in the reaction ${ }^{2} \mathrm{H}$ $\left({ }^{6} \mathrm{Li}, \alpha\right){ }^{4} \mathrm{He}$ at $\theta_{\mathrm{cm}}=90^{\circ}$ and $E_{\text {lab }}=21.5 \mathrm{MeV}$ (see text).

Obviously all depolarizing effects during the production and acceleration of the beam can be estimated by at most a few percent.

5. ${ }^{7} \mathrm{Li}$ polarization. - The ${ }^{7} \mathrm{Li}$ alignment is calibrated in the ${ }^{1} \mathrm{H}\left({ }^{7} \overrightarrow{\mathrm{Li}}, \alpha\right){ }^{4} \mathrm{He}$ reaction at $\theta=0^{\circ}[14]$. It can be shown that ${ }^{7} \mathrm{Li}$ projectiles with $m_{I}= \pm 1 / 2$ only, defined relative to the beam axis, contribute to the reaction. Therefore the analysing power is:

$$
t_{20}\left(\theta=0^{\circ}\right)=-1 \text {. }
$$

The same relation holds for the reaction ${ }^{1} \mathrm{H}\left({ }^{23} \mathrm{Na}, \alpha\right){ }^{20} \mathrm{Ne}$ (g.s.) which will be used for measuring the ${ }^{23} \mathrm{Na}$ polarization.

The $7 \mathrm{Li}$ polarization is monitored continously during the experiments by the reaction described. It turned out to be more sensitive to the adjustment of various source components as the hf transitions and the ionizer, compared to the $6 \mathrm{Li}$ case. The alignment $t_{20}$ was between 60 and $70 \%$ of the maximum value obtainable by the hf transitions (see Table II), that is 30 to $35 \%$ of the absolute maximum.

6. Conclusions. - The source for negative polarized lithium ions is reliably working since 1974. The polarization of the ${ }^{6} \mathrm{Li}$ beam, produced by a standard hf transition scheme [8], is about $95 \%$ of the maximum value and of excellent stability. The flexibility of the $\mathrm{hf}$ transition system satisfies very well the experimental requirements.

The production of the ${ }^{7} \mathrm{Li}$ beam available only since half a year, causes some complications due to the increased number of hfs states and the temperature dependent depolarization at the ionizer surface. The present system of one weak field transition and two $\sigma$ strong field transitions delivers up to $35 \%$ of the maximum polarization. Substantial improvement could be achieved by using $\pi$ transitions [16].

The amount of residual ${ }^{23} \mathrm{Na}$ polarization, which has not yet been measured, will probably give some new insight in hyperfine interaction processes at the ionizer surface and in a highly stripped ion. Furthermore a polarized ${ }^{23} \mathrm{Na}$ beam would enable experiments with aligned deformed projectiles regarded as real heavy ions.
[1] Proc. $4^{\text {th }}$ Int. Symp. on Polarization Phenomena..., (W. Gruebler and V. König (Ed.)) Zürich 1975.

[2] ClegG T. B., in ref. [1], 111.

[3] HARDEKOPF R. A., in ref. [1], 865.

[4] Steffens E., Ebinghaus H., Fieldler F., Bethge K., EngeLHARDT G., SCHÄFER R., WeISS W., FICK D., Nucl. Instrum. Methods. 124 (1975) 601.

[5] Steffens E., Dreves W., Ebinghaus H., Köhne M., FieldLER F., Egelhof P., ENGelhardt G., Kassen D., SChäFER R., WeISS W., Fick D., Nucl. Instrum. Methods, to be published.

[6] FICK D., in ref. [1], 357.

[7] Haeberli W., in Nucl. Spectr. and React. Part A, J. Cerny (ed.), New York 1974, 151.
[8] Glavish H. F., Proc. of the Symp. on Ion Sources..., Brookhaven Nat. Lab. 1971, 207.

[9] Power Signal Source, Mod. 125A, AILTECH, City of Industry (CA) USA.

[10] Proc. $3^{\text {nd }}$ Int. Symp. on Polarization Phenomena..., (H. H. Barschall and W. Haeberli (Ed.)), Madison 1970.

[11] Madison convention, ref. [10], p. Xxv; Darden S. E., ref. [10], 39; KeAton P. W., ref. [10], 422.

[12] Datz S. and Taylor E. H., J. Chem. Phys. 25 (1956) 389.

[13] Kaminski M., Ann. Phys. 18 (1966) 53; Daley H. L., Yahiku A. Y., and Perel J., J. Chem. Phys. 52 (1970) 3577.

[14] Dreves W., et al., to be published.

[15] KASSEN D., et al., to be published.

[16] StefFens E., IEEE Trans. Nucl. Sci. NS-23 (1976) 1145. 